\title{
Capsule Commentary on Faerber et al., Content Analysis of False and Misleading Claims in Television Advertising for Prescription and Nonprescription Drugs
}

\author{
G. Caleb Alexander, MD, MS \\ Department of Epidemiology, Johns Hopkins Bloomberg School of Public Health, Baltimore, MD, USA.
}

J Gen Intern Med 29(1):180

DOI: $10.1007 / \mathrm{s} 11606-013-2622-\mathrm{y}$

(c) Society of General Internal Medicine 2013

$\mathrm{T}$ he study by Faerber and Kreling ${ }^{1}$ adds to a growing literature about direct-to-consumer advertising (DTCA), a unique form of drug advertising prohibited in most of the world. They found that of television ads airing from 2008 to 2010, $33 \%$ were objectively true, $57 \%$ were potentially misleading and $10 \%$ were just outright ("pants on fire") false. There were more objectively true claims and fewer false claims for prescription than non-prescription ads.

The authors used a well-defined protocol and the high inter-rater agreement between coders was reassuring. The differences between prescription and non-prescription drugs were of interest - one has to wonder whether differences in the regulatory environment of the Food and Drug Administration (FDA) and Federal Trade Commission (FTC) account for this. Although the authors only examined a subset of claims from a subset of ads from a subset of DTCA, there is no obvious reason that this would substantially bias their results. They acknowledge that their endpoint was a proximal one-some of the claims may not have misled consumers, and consumers may have been misled without consequential changes in their clinical care.

Perhaps most vexing is that while many of the claims were misleading, they were not illegal per se. While this study may be welcome ammunition for those opposing DTCA, others will continue to argue that DTCA serves a valuable social good by leading to case-finding and by destigmatizing diseases such as depression. Interestingly, despite the volume of rhetoric, there is remarkably little evidence about DTCA's true effects on prescription drug utilization and health outcomes, though most research suggests DTCA is associated with an increase in drug utilization, patient requests for specific drugs, and physicians' confidence in prescribing. ${ }^{2}$

Although DTCA remains a lightning rod for controversy, it remains highly concentrated in a small number of products and accounts for only $15 \%$ or so of prescription drug marketing. ${ }^{3}$ Tried and true methods of pharmaceutical marketing, detailing visits, and free office samples ${ }^{4}$ continue to account for the lion share of promotion; this is not surprising, given how effective these methods are at changing physician behavior. ${ }^{5}$

Conflict of Interest: Dr. Alexander is an ad hoc member of the FDA's Drug Safety and Risk Management Advisory Committee, serves as a paid consultant to IMS Health, and serves on an IMS Health scientific advisory board. This arrangement has been reviewed and approved by the Johns Hopkins University in accordance with its conflict of interest policies.

Corresponding Author: G. Caleb Alexander, MD, MS; Department of Epidemiology, Johns Hopkins Bloomberg School of Public Health, Baltimore, MD 21205, USA (e-mail: galexand@jhsph.edu).

\section{REFERENCES}

1. Faerber AE, Kreling DH. Content analysis of false and misleading claims in television advertising for prescription and nonprescription drugs. J Gen Intern Med. 2013. doi:10.1007/s11606-013-2604-0.

2. Gilbody S, Wilson P, Watt I. Benefits and harms of direct to consumer advertising: a systematic review. Qual Saf Health Care. 2005; 14:246-50.

3. Kornfield R, Donohue J, Berndt ER, Alexander GC. Changing promotion of prescription drugs to consumers and providers, 2001-2010. PLoS ONE. 2013;8:1-7.

4. Alexander GC, Zhang J, Basu A. Characteristics of patients receiving pharmaceutical samples and association between sample receipt and outof-pocket prescription costs. Med Care. 2008;46:394-402.

5. Wazana A. Physicians and the pharmaceutical industry: is a gift ever just a gift? JAMA. 2000;283:373-80.

Published online October 1, 2013 